\title{
Metafikcja a realizm iluzyjny w Serii niefortunnych zdarzeń Lemony'ego Snicketa i jej serialowej adaptacji
}

\section{Abstrakt:}

Przedmiotem artykułu jest adaptacja metaleptycznych i metafikcjonalnych elementów powieściowej Serii niefortunnych zdarzeń Lemony'ego Snicketa (1999-2006) w powstałym na jej podstawie serialu (2017-2019). Celem autorki jest wykazanie, w jaki sposób poglądy twórców na właściwości medium filmowego wpłynęły na redukcję tych elementów, eksplicytację i ujednoznacznienie sensów tekstu źródłowego oraz poddanie fabuły tradycyjnym konwencjom narracyjnym.

\section{Słowa kluczowe:}

adaptacja, konwencje narracyjne, Lemony Snicket, literatura dziecięca, metafikcja, metalepsa, narracja, Seria niefortunnych zdarzeń

\section{Metafiction and Illusionary Realism in Lemony Snicket's A Series of Unfortunate Events and Its Adaptation as a TV Series}

\section{Abstract:}

The article discusses the metaleptic and metafictional elements present in Lemony Snicket's A Series of Unfortunate Events (1999-2006) as adapted for the TV series based on the novels (2017-2019). The aim is to demonstrate how, as a result of the creators' views on the particularities of the film medium, these elements are reduced, meanings are made more explicit and less ambiguous, and the plot is subjected to traditional narrative conventions.

Key words:

adaptation, narrative conventions, Lemony Snicket, children's literature, metafiction, metalepsis, narrative, A Series of Unfortunate Events

* Barbara Kaczyńska - mgr, przygotowuje rozprawę doktorską w Instytucie Lingwistyki Stosowanej Wydziału Lingwistyki Stosowanej na Uniwersytecie Warszawskim dotyczącą recepcji XVII- i XVIII-wiecznej francuskiej baśni literackiej w polskiej literaturze dziecięcej. Kontakt: b.kaczynska@uw.edu.pl. 


\section{Wprowadzenie}

aniel [Handler] dużo mówił o różnicy między książkami a telewizją 2) i o tym, że wizualne medium wymaga, by rzeczy były powiedziane bardziej wprost. Zawsze więc wiedzieliśmy, że w serialu trzeba wyjaśnić część tajemnic, których nie rozwiązano w książkach (lub [ujawnić te rozwiązania,]

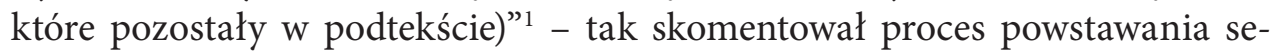
rialowej Serii niefortunnych zdarzeń (Handler, Lam, Sonnenfeld, 2017-2019) ${ }^{2}$ jeden z jej scenarzystów, Joe Tracz (2019), wyjaśniając przyczyny niektórych różnic między literackim tekstem źródłowym a adaptacją. Zaprezentowane przez twórcę podejście do wizualnego medium musiało skutkować dążeniem do eksplicytacji i ujednoznaczniania przy przekładaniu na ekran książek, które programowo wręcz unikają odpowiedzi na zadane w nich pytania. Celem niniejszego artykułu jest prześledzenie transformacji narracji w Serii niefortunnych zdarzeń, ze szczególnym uwzględnieniem aspektów metafikcjonalnych i metaleptycznych literackiego tekstu źródłowego i jego serialowej adaptacji.

\section{„Taka jest prawda”, czyli przykład metafikcji w literaturze dziecięcej}

Powieściowa Seria niefortunnych zdarzeń składa się z trzynastu tomów, wydanych pierwotnie w latach 1999-2006 (polski przekład Jolanty Kozak w latach 2002-2007), firmowanych nazwiskiem Lemony'ego Snicketa i ilustrowanych przez Bretta Helquista. Przeznaczony dla młodego czytelnika cykl w demonstracyjny sposób odżegnuje się od stereotypowych, idyllicznych lub dydaktycznych konwencji literatury dziecięcej, parodiując je i krytykując. Kolejne tomy realizują - zaczerpnięty z moralizatorskiej powieści wiktoriańskiej i budzącej grozę powieści gotyckiej - schemat prześladowania szlachetnych sierot przez chciwego łotra, ale prawość serca nie gwarantuje Wioletce, Klausowi i Słoneczku Baudelaire'om triumfu nad Hrabią Olafem (Austin, 2013) - dzięki inteligencji i przytomności umysłu dzieciom co prawda udaje się wielokrotnie uniknąć najgorszego, jednak antagonista zawsze ucieka, co nieuchronnie zapowiada ponowny konflikt w kolejnej części serii.

Jeśli nie podano inaczej, wszystkie tłumaczenia autorki artykułu - Barbary Kaczyńskiej.

2 W 2004 roku powstała adaptacja Serii niefortunnych zdarzeń w formie filmu pełnometrażowego (MacDonald, Parkes, Van Wyck, Silberling, 2004), jednak nie jest ona przedmiotem niniejszego artykułu. 
Schemat ten jest coraz śmielej modyfikowany w późniejszych tomach cyklu. Ich fabuła i cały świat przedstawiony ulegają komplikacji poprzez wprowadzenie WZS (w oryginale V.F.D.) - tajemniczej organizacji gaszącej pożary, promującej wiedzę i rozwój pasji, ale z niejasnych przyczyn rozdartej schizmą jakiś czas przed wydarzeniami opisywanymi w tych powieściach. Baudelaire'owie poszukują odpowiedzi na coraz liczniejsze pytania (o dokładny charakter organizacji, jej związki z ich rodziną, przyczyny rozłamu i zawartość enigmatycznej cukiernicy, o którą walczą obydwie strony schizmy), ale na większość z nich nigdy nie znajdują odpowiedzi. Jedynym pewnikiem w Snicketowskim świecie pozostaje przesycający go czarny humor: już w tytule serii i poszczególnych tomów - od Przykrego początku (Snicket, 1999/2002a), poprzez Tartak tortur (Snicket, 2000/2002d) i Szkodliwy szpital (Snicket, 2001/2003c), aż po Koniec końców (Snicket, 2006/2007) - zasygnalizowany został hiperboliczny, a przez to komiczny pesymizm (Slany, 2016, s. 219), prezentowany konsekwentnie przez nadwrażliwego narratora, który przy każdej okazji zapowiada nieszczęśliwe zakończenie i ostrzega czytelnika przed nieprzyjemnościami, jakie czekają bohaterów, jednym tchem wymieniając m.in. kuszę harpunową, solarium na dachu i źle przyrządzone curry (Snicket, 2005/2006a, czwarta strona okładki). Ta przekorna, prowokacyjna strategia antyrekomendacyjna „jeśli nie [zniechęci] do zakupu [książek], to na pewno skuteczniej [spełni] swą funkcję perswazyjną" (Loewe, 2016, s. 383), stanowiąc jeden z elementów wielopoziomowej gry z gatunkami i konwencjami literackimi oraz paraliterackimi³

Osobliwy narrator - najbardziej rzucający się w oczy wyróżnik serii - jest interesujący szczególnie ze względu na swój metaleptyczny status ontologiczny, przekraczający podziały między poziomem ekstra- i intradiegetycznym. Lemony Snicket to nie tylko postać należąca do świata przedstawionego Serii niefortunnych zdarzeń, lecz także pseudonim literacki Daniela Handlera, prezentowany jednocześnie $\mathrm{w}$ paratekstach (okładka, noty o autorze $\mathrm{z}$ dodatkiem fotografii przedstawiających go zawsze $\mathrm{z}$ daleka i od tyłu, listy do czytelnika i do wydawcy na końcu książek, materiały promocyjne, spotkania autorskie) jako realnie istniejąca osoba, odrębna od Handlera, który dawniej przedstawiał się tylko jako agent Snicketa. Zarazem jednak hipotetyczny odbiorca - również dziecięcy - nie ma wątpliwości co do fikcyjności Snicketa; świadom tekstowej i paratekstowej gry, jest gotów ją podtrzymywać (Magnusson, 2012, s. 100).

\footnotetext{
Antyrekomendacja, a także podkreślanie autonomii czytelnika (a w przypadku serialowej adaptacji - widza), skutkujące dowartościowaniem potencjalnego odbiorcy, wpisują się oczywiście w komercyjny kontekst serii, na który zwraca uwagę Loewe (2016), nie wchodzi on jednak w zakres rozważań przedstawionych w niniejszym artykule.
} 
W ten sposób „sfera diegezy zostaje częściowo wyprowadzona poza narrację, która ją stworzyła" (Statkiewicz-Zawadzka, 2010, s. 239), a Handler może zdystansować się od „własnej utowarowionej [commodified] obecności jako autora [literatury dziecięcej]" (Magnusson, 2012, s. 86).

Snicket jako postać pozostaje na uboczu książkowego świata przedstawionego i unika jasnego wykładu własnej biografii, choć przytacza z niej pewne szczegóły „jedynie po to, aby uczynić naszą powieść jeszcze przykrzejszą, bardziej irytującą i niewiarygodną, niż byłaby bez marginesów" (Snicket, 2001/2003c, s. 99). Z tych sporadycznych wzmianek wynika, że należał do WZS, znał rodziców Baudelaire’ów, przeżył nieszczęśliwą historię miłosną z nieżyjącą już Beatrycze, której to kobiecie dedykuje każdą z książek, i miał coś wspólnego z kradzieżą tajemniczej cukiernicy - wszystko to jednak wydarzyło się „bardzo dawno temu”, a na zakończenie jego historii „nikt już nie ma wpływu" (s. 99). Twierdzi, że dokumentowanie dziejów Baudelaire’ów jest jego przykrym obowiązkiem. Wielokrotnie też podkreśla tragizm i prawdziwość ich historii, co z jednej strony odróżnia Serię niefortunnych zdarzeń od stereotypowych, „zmyślonych” na potrzeby dzieci optymistycznych fabuł, a z drugiej - skutkuje metafikcjonalną ${ }^{4}$ grą z czytelnikiem świadomym konwencjonalności zapewnień o autentyzmie opisywanych wydarzeń.

Upierając się przy swojej prawdomówności, Snicket (2003/2004b, s. 29) twierdzi, że zbieranie wycinków z gazet oraz przeczesywanie z latarką i słownikiem rymów miejsc odwiedzonych przez Baudelaire'ów pozwoliło mu ustalić dokładny przebieg wydarzeń, a nawet rozmów między bohaterami. Sam świat przedstawiony również roi się od absurdów i nieprawdopodobnych sytuacji, począwszy od postaci Słoneczka, która już jako niemowlę jest zdolna do głębokich przemyśleń i może pracować jako sekretarka lub robotnica w tartaku, a skończywszy na wynalazkach, które ratują Baudelaire'ów z tarapatów, jak wędka zrobiona z gumy do żucia i na tyle mocna, by przesunąć kłodę, albo mieszanka dwudziestu sześciu lepkich produktów spożywczych użyta do zahamowania

4 Metafikcja [metafiction] definiowana jest jako literatura „autorefleksyjna” albo „samoświadoma” (czyli świadoma swojego statusu jako literatury - konstruowanej fikcji), „eksplorowanie teorii literatury poprzez praktykę [wyróżnienia oryginalne] pisania literatury” (Waugh, 1984, s. 2), „graniczny dyskurs, sposób pisania, który sam siebie plasuje na granicy między literaturą a krytyką i tę granicę przyjmuje sobie za temat” (Currie, 1995, s. 2). Termin ten jest używany w artykule zamiast częstszego w literaturze polskiej określenia „autotematyzm" ze względu na zastrzė̇enia wyrażone przez Dietera De Bruyna (2006, s. 51-53), według którego polski termin zbyt duży nacisk kładzie na „konkretny temat dzieła literackiego, a nie na immanentną autorefleksyjność literatury jako takiej” (s. 51) i nie uwzględnia udziału czytelnika w konstruowaniu sensu utworu. 
barakowozu pędzącego w dół zbocza. Snicket jest zatem narratorem niewiarygodnym, ale nie dlatego, że pod jego „stronniczą” lub „błędną" narracją ukrywa się jakaś „prawdziwa” (w obrębie diegezy) historia, lecz dlatego, że upiera się przy istnieniu „prawdziwej” historii, podczas gdy w rzeczywistości nie istnieje nic prócz jego opowieści. Narrator wielokrotnie podkreśla zresztą konstrukcję fabularną i językowy kształt książek, nieustannie definiując wyrażenia używane przez siebie i przez bohaterów oraz zapowiadając zwroty akcji, np. gdy mówi: „W operze La Forza del Destino postacie [...] upuszczają na ziemię rewolwer, który wypala i przypadkiem kogoś zabija, całkiem (cóż za niesamowity zbieg okoliczności) jak w rozdziale dziewiątym naszej książki” (Snicket, 2005/2006a, s. 25). Oczywiście o żadnym zbiegu okoliczności nie ma mowy - podobieństwo do opery to celowy zabieg autorski. Zwracając na niego uwagę, a jednocześnie powołując się na konwencję realizmu iluzyjnego, narrator doprowadza do absurdu obowiązujący zwykle w literaturze pakt oparty na negowaniu fikcyjności fikcji i tym samym doprowadza do jego zerwania. Jak pisze Gérard Genette (2004):

Na ten pakt nikt nie daje się nabrać, może oprócz najmłodszych lub najbardziej naiwnych czytelników, jednak zerwanie go stanowi niemniej transgresję, która musi zachwiać słynnym „dobrowolnym zawieszeniem niewiary” na rzecz swego rodzaju żartobliwego poczucia współudziału (s. 23).

Należy bowiem dodać, że metafikcjonalny zabieg zwrócenia uwagi odbiorcy na fikcyjny charakter czytanej historii jako narracyjnej i językowej konstrukcji paradoksalnie nie prowadzi do jego alienacji, lecz stanowi zaproszenie do intelektualnego i emocjonalnego zaangażowania się we współtworzenie sensu dzieła (Hutcheon, 1984, s. 7, 22-23).

Metafikcjonalne aspekty Serii niefortunnych zdarzeń odwracają tradycyjną relację władzy w literaturze dziecięcej. Dorosły narrator nie zajmuje wcale pozycji nadrzędnej ani nad dziecięcymi bohaterami, ani nad dziecięcymi czytelnikami. Wzdychając nad losem Baudelaire’ów, często przyznaje się do własnej słabości, a nawet komicznej skłonności do histerii:

Przyznam się wam, że gdybym nie był w tej chwili na pokładzie jachtu mej przyjaciółki Beli, gdzie piszę te słowa, lecz na miejscu Wioletki, i gdybym miał tylko parę minut na otwarcie zatrzaśniętej walizki, zapewne poddałbym się, widząc beznadziejność sytuacji. Osunąłbym się na podłogę i bębnił pięściami w dywan, zadając sobie pytanie, czemu życie jest tak strasznie niesprawiedliwe i pełne kłopotów. Na szczęście dla całej trójki Baudelaire’ów Wioletka była dzielniejsza ode mnie [...] (Snicket, 1999/2002b, s. 166). 
Liczne samoobjaśnienia - w rodzaju „[...] Klaus [spoglądał] z miną asertywną, co znaczy "uprzejmie pewną siebie«" (Snicket, 2002c, s. 209) - pozornie wskazują na edukacyjną funkcję narracji i pragnienie wzbogacenia słownictwa czytelnika, często jednak pod formą definicji kryją się opisy sytuacji, np.: „[...] oblałby się zimnym potem, co tutaj znaczy: »zdenerwowałby się bardzo rozmową, którą właśnie podsłuchiwał"” (Snicket, 2005/2006a, s. 120). Czasem definicje mogą być w sposób oczywisty błędne, jak wtedy, gdy narrator zabiera się do tłumaczenia francuskiego określenia cul-de-sac i po długim wywodzie dochodzi do wniosku, że należy przełożyć je jako: „U wylotu ciemnego korytarza sieroty Baudelaire znalazły cały szereg (kogo? czego?) tajemniczych okoliczności" (Snicket, 2001/2003a, s. 218). Sam przyznaje, że język jest „tajemniczy i mylący” (Snicket, 2006/2007, s. 51), jak gdyby podważał własną kompetencję lingwistyczną. Rzadko też podejmuje się objaśnienia czytelnikom licznych intertekstualnych nawiązań, które obejmują Morsa i Stolarza z Alicji po tamtej stronie lustra autorstwa Lewisa Carrolla (1871/1999), ale i Annę Kareninę Lwa Tołstoja (1877/1984) czy Moby Dicka Hermana Melville’a (1851/2002); kiedy tłumaczy czytelnikowi fragment Syna swego kraju ${ }^{5}$ Richarda Wrighta (1940/1980), skromnie wyznaje, że sam rozgryzł jego sens „dzięki żmudnym dociekaniom" (Snicket, 2005/2006a, s. 361). Jawi się jako bezsilny wobec opisywanego świata i używanego języka, zrzeka się odpowiedzialności za opowiadaną historię i przedstawia samego siebie jako zakładnika narracji, zobowiązanego do snucia jej wbrew swojej woli - podczas gdy dziecięcy czytelnik może w każdej chwili odłożyć książkę, do czego Snicket go zresztą zachęca. Jeśli mimo to odbiorca ma aktywnie kontynuować lekturę i czerpać z niej przyjemność, musi samodzielnie rozpoznać ironiczny pseudodydaktyzm stylu i umowność rzeczywistości, której staje się współtwórcą.

\section{Rozpad narracji}

Ostatnie dwa tomy serii - Przedostatnia pułapka (Snicket, 2005/2006a) oraz Koniec końców (Snicket, 2006/2007) - stanowią dodatkowe wyzwanie dla zdolności poznawczych czytelnika i mogą zrazić go, jeżeli oczekuje konwencjonalnego rozwiązania akcji. Wprowadzają nowe tajemnice: zostaje np. zasugerowane, że rodzice Baudelaire'ów, do tej pory stanowiący we wspomnieniach bohaterów bastion dobra, byli winni śmierci rodziców Hrabiego Olafa, co każe

5 Tytuł oryginalny to Native Son; Jolanta Kozak (Snicket, 2005/2006a, s. 361) podaje w tłumaczeniu tytuł powieści Wrighta jako Syn tej ziemi. 
kwestionować ich moralność. Co więcej, tomy te nie udzielają odpowiedzi na pytania o przyczyny schizmy i zawartość cukiernicy. Tym samym wyłamują się z konwencji kompozycyjnych obowiązujących tradycyjnie w literaturze, mimo że jednocześnie mocno je podkreślają.

W Przedostatniej pułapce bohaterowie trafiają do Hotelu Ostateczność, który w oryginale nosi nazwę Hotel Denouement, co jest terminem oznaczającym rozwiązanie akcji. Narrator komentuje: „Ostateczność [denouement] to moment rozwikłania splątanych wątków historii, której prawda nareszcie ujawnia się światu. Nie należy jednak mylić ostateczności z zakończeniem historii" (Snicket, 2005/2006a, s. 184). Do hotelu zjeżdżają niemal wszyscy, którzy mieli styczność $\mathrm{z}$ Baudelaire’ami $\mathrm{w}$ jedenastu poprzednich tomach. Te postaci - reprezentujące cały bez mała świat przedstawiony - gromadzą się w jednym miejscu, by wziąć udział w rozprawie sądowej, podczas której każda tajemnica ma zostać wyjaśniona, Hrabia Olaf - skazany, a sieroty Baudelaire - uwolnione od ciążącego na nich zarzutu morderstwa. Snicket (2005/2006a) nie pozostawia jednak nadziei: ani bohaterowie, ani czytelnik „nie urodzili się wczoraj” (s. 210), znają konwencje tej historii i wiedzą, że nie może mieć szczęśliwego zakończenia.

Nie wiedzą natomiast, komu mogą zaufać, i nie są w stanie odróżnić dobra od zła ani prawdy od pozoru. Jeden z kierowników hotelu - Frank Ostateczność - to szlachetny sprzymierzeniec, drugi - Ernest Ostateczność - jest nikczemnym przeciwnikiem, obaj jednak wyglądają identycznie i zachowują się równie tajemniczo, nie sposób więc ustalić, kto jest kim. Ta niepewność dotyczy też samego hotelu, którego szyld napisany jest pismem lustrzanym i daje się prawidłowo odczytać jedynie w sadzawce przed budynkiem, mieszczącej tajną bibliotekę. Prawdziwy Hotel Ostateczność ukrywa się zatem pod odbiciem w wodzie, a lustrzaną podobizną jest namacalny budynek. Kategorie iluzji i prawdy ulegają rozchwianiu, a nawet odwróceniu.

Zgodnie z zapowiedzią narratora, w rozdziale dziewiątym dochodzi do wypadku, w którym ginie trzeci kierownik hotelu. Baudelaire’owie zostają oskarżeni o kolejne morderstwo. Gdy tajemniczy mężczyzna proponuje im ucieczkę taksówką, nie wiedzą, czy mogą mu zaufać: „[...] zrozumiały, że nie potrafią odpowiedzieć sobie nawet na pytanie, czy same są dobre, czy złe a cóż dopiero mówić o ocenie tajemniczego mężczyzny" (Snicket, 2005/2006a, s. 257). W rezultacie nie przyjmują pomocy mężczyzny - a jest nim najprawdopodobniej sam Snicket, który na tych kilku stronach jedyny raz styka się bezpośrednio z Baudelaire'ami i nie ingeruje $\mathrm{w}$ ich historię. Nie próbuje narzucić dzieciom swojej władzy, lecz pozostawia im swobodę działania, choć sam nie potrafi osądzić, czy podjęły słuszną decyzję. 
Proces Olafa i Baudelaire'ów przeradza się w kakofonię i chaos, gdy wszyscy obecni z zawiązanymi oczami (ponieważ „sprawiedliwość jest ślepa" - Snicket, 2005/2006a, s. 277) składają przed sądem coraz bardziej absurdalne dowody. Bohaterowie pozornie mają nareszcie szansę na opowiedzenie swojej własnej historii i na to, by owej historii wysłuchano, po tym, jak przez dwanaście tomów traktowano ich albo jako niedojrzałych mitomanów, albo młodocianych przestępców. Prędko jednak okazuje się, że nie mogą liczyć na skorumpowany wymiar sprawiedliwości, tak jak nie mogli liczyć na większość dorosłych, których spotkali na swojej drodze, a którzy byli albo niemoralni, albo nieudolni. W zamieszaniu Baudelaire’owie zmuszeni są wzniecić pożar, z którego uciekają razem z Hrabią Olafem. Los wszystkich pozostałych postaci pozostaje nieznany, dla dalszej konstrukcji powieści nie ma on jednak znaczenia. W sensie narracyjnym postaci ulegają zatem destrukcji.

Rozwiązanie akcji, które obiecywał Hotel Denouement, ma zatem specyficzny charakter. Wiele pytań nie doczekało się odpowiedzi, a wiele wątków zostało raczej uciętych niż zakończonych. Natomiast w Końcu końców (Snicket, 2006/2007), w którym Baudelaire'owie trafiają na rajską wyspę poza światem, rzeczywiście dochodzi do swego rodzaju rozwiązania, czy raczej rozplecenia sieci opowieści. Fabuła utworu zostaje przedstawiona jako wybrany arbitralnie wycinek z niepojętej mnogości przenikających się historii, w których losy Baudelaire'ów są zaledwie epizodem. Seria niefortunnych zdarzeń nie jest już tylko tytułem serii. Tak samo określona zostaje kronika wyspy, nazwana dość rozwlekle: Ludzie spisuja w tej księdze swoje historie od czasu, gdy fala wyrzuciła na wyspę pierwszych rozbitków, i opowieści te sq w jakiś sposób z soba powiązane. Każde pytanie prowadzi do następnego, i tak dalej, $i$ tak dalej. To jak $z$ obieraniem cebuli (s. 218). Narrator przyznaje się do konieczności zakończenia książki in medias res, ponieważ „świat jest stale in medias res, czyli »w środku opowieści«, i nie sposób rozwiązać w nim do końca jakiejkolwiek tajemnicy ani doszukać się ostatecznej przyczyny problemów" (s. 285). Gdy świat przedstawiony zaczyna stopniem skomplikowania przypominać świat empiryczny, następuje jego rozpad. Historia Baudelaire'ów dobiega końca, ponieważ wyzwalają się oni nie tylko z konwencji stereotypowej, dydaktycznej i idyllicznej literatury dziecięcej, lecz także z konwencji, której podlegały w mniejszym lub większym stopniu wszystkie poprzednie części Serii niefortunnych zdarzeń: Hrabia Olaf umiera, a bohaterowie stają się przybranymi rodzicami osieroconego niemowlęcia, któremu na cześć swojej nieżyjącej matki nadają imię Beatrycze. Co więcej, na końcu Końca końców znajduje się Rozdział czternasty, opatrzony własną stroną tytułową, metryką i numeracją stron; z jednej strony jest to przełamanie schematu wcześniejszych 
tomów, wszystkich bez wyjątku złożonych z trzynastu rozdziałów, z drugiej zaś - czternasta część całej serii, wykraczająca poza jej „pechową” strukturę. W Rozdziale czternastym Baudelaire'owie sami stają się narratorami swojej historii, spisując ją w kronice wyspy. Pogodziwszy się z niemożnością uzyskania odpowiedzi na wszystkie pytania, mimo to ufają swojej wiedzy oraz umiejętnościom i mają odwagę opuścić wyspę - zdają sobie bowiem sprawę, że zapewnia ona jedynie złudne schronienie. Osiągnąwszy wreszcie całkowitą niezależność, wypływają na spotkanie z Wielką Niewiadomą - upostaciowioną tajemnicą, objawiającą się w morskich głębinach jako olbrzymi znak zapytania, i w ten sposób wymykają się całkowicie poza zasięg wiedzy i władzy bezsilnego, milknącego narratora.

\section{Serialowa adaptacja. Emancypacja i streamlining świata przedstawionego}

Zakończenie powieści przynosi rzecz jasna rozczarowanie tym czytelnikom, którzy oczekują, że książka zgodnie z literacką konwencją odpowie na postawione wcześniej pytania, dlatego też np. niektórzy użytkownicy portalu Goodreads (b.a., b.d.) skłonni są podejrzewać autora o lenistwo i nieumiejętność wymyślenia satysfakcjonującego rozwiązania wymyślonych wcześniej zagadek. Rozpad fikcyjnej opowieści pod wpływem metafikcjonalnej refleksji okazał się również problematyczny dla twórców dystrybuowanej przez Netflix Serii niefortunnych zdarzeń (Handler, Lam, Sonnenfeld, 2017-2019). Cytowany już scenarzysta Joe Tracz (2019) wyznaje:

Byłem obrońcą Końca końców od momentu, gdy ta książka się ukazała; jest coś tak wstrząsającego, a jednak doskonałego w tym, jak odmawia udzielenia łatwych odpowiedzi. Ale główna myśl serialu jest nieco inna. Zamiast opozycji „znane” - „nieznane”, nasze ostatnie odcinki dotyczą raczej ukrywania się przed światem lub działania w nim [...]. Poza tym jest jeszcze różnica między serialem telewizyjnym a książką [...]. Film, nawet osadzony w takim absurdalnym świecie jak nasz [...], jest bardziej dosłowny, bardziej rzeczywisty.

Wydaje się zatem, że według twórców serialu (do których należał sam Handler) obraz musi powiedzieć więcej niż tysiąc słów i nie ma w filmie ucieczki przed realizmem iluzyjnym. Jest to również podejście zakładające ograniczone możliwości dochowania mitycznej „wierności” w przekładzie intersemiotycznym, jakim jest adaptacja, co miałoby wynikać z samej różnicy systemów semiotycznych literatury i filmu (Helman, 2014, s. 9). Nie rozstrzygając zasadności tego 
przekonania, warto tym niemniej zbadać, jakie skutki miało ono dla powstałego na jego podstawie utworu.

W istocie, zgodnie z poglądem Tracza o większej dosłowności filmowej diegezy, adaptacja Serii niefortunnych zdarzeń wydaje się pod wieloma względami ograniczać absurdalność świata przedstawionego, rezygnując np. z najbardziej nieprawdopodobnych wynalazków Baudelaire'ów albo lustrzanego szyldu Hotelu Ostateczność ${ }^{6}$. Niektóre sytuacje ulegają racjonalizacji. Dobrym przykładem jest fragment Zjezdnego zbocza, w którym bohaterowie, aby dostać się do głównej siedziby WZS, muszą wpisać na klawiaturze szyfrowanego zamka hasło: główne przesłanie Anny Kareniny, bez wahania sformułowane przez Klausa w słowach: „Sielski żywot, oparty na prostocie moralnej, jest mimo swojej monotonii wartościowszy od burzliwych uniesień, które zawsze kończą się tragedią" (Snicket, 2003/2004b, s. 153). Założenie, że istnieje jeden prawidłowy sposób wyrażenia głównej myśli powieści, która może w związku z tym posłużyć jako hasło otwierające automatyczny zamek, jest oczywiście absurdalne, a zatem komiczne. W serialu (Handler, Teplitzky, 2019) otrzymuje ono jednak racjonalne wytłumaczenie, okazuje się bowiem, że swego czasu matka Baudelaire’ów kazała im nauczyć się tego zdania na pamięć, spodziewając się, że kiedyś będą go potrzebować.

Lemony Snicket - grany przez Patricka Warburtona - podobnie jak w książkach balansuje na granicy między diegezą a odbiorcą. Aż do odcinka Krwiożerczy karnawat. Część 1 (Tracz, Peristere, 2018), siedemnastego z dwudziestu pięciu w całym serialu, nie widzimy jego interakcji z innymi postaciami: nawet gdy pojawia się razem z nimi na ekranie, nigdy nie jest uczestnikiem tej samej sceny i zwraca się wyłącznie do widza. Jednocześnie jednak jego metaleptyczny i metafikcjonalny charakter już w pierwszym sezonie ulega redukcji i modyfikacji (Kaczyńska, 2018). Wprawdzie w napisach początkowych pojawia się wzmianka, że serial oparto na książkach Lemony'ego Snicketa, on sam nie jest już jednak prezentowany ani jako twórca serialu, ani nawet jako jedyna instancja tworząca opowieść. Materia historii nie ogranicza się do słów narratora, lecz tworzona jest przez szereg różnych systemów znakowych, takich jak dialogi i zachowania postaci, scenografia czy muzyka. Opowieść „dzieje się” na oczach widza w dużej mierze niezależnie od interwencji narratora. Te ostatnie ograniczają się zresztą wyłącznie do historii Baudelaire'ów, tymczasem w serialu wprowadzono wiele wątków nieobecnych w książkach i wolnych od narratorskich objaśnień, dygresji i glos. W związku z tym Snicket staje się raczej

6 Godny uwagi jest fakt, że filmowa adaptacja, sama oparta na iluzji obrazu, rezygnuje z tej metafory ukazującej iluzję obrazu, choć temat złudności pozorów pojawia się w komentarzu narratora (Tracz, Sonnenfeld, 2019a). 
prezenterem lub komentatorem, co z kolei nie kłóci się z jego twierdzeniami, że opisuje prawdziwą historię, która - dzięki werystycznemu przedstawieniu wizualnemu - zyskuje w oczach widza status obiektywnej rzeczywistości (Ostaszewski, 2018, s. 214).

Oczywiście chodzi nadal o rzeczywistość fikcyjną, nie empiryczną, ponieważ i w tym przypadku działa pakt, na który według słów Gérarda Genette’a (2004) „nikt nie daje się nabrać” (s. 23). Faktem pozostaje jednak, że serialowa Seria niefortunnych zdarzeń wystawia ten pakt na próbę w mniejszym stopniu niż książki, choć i ona nie jest pozbawiona aspektów metafikcjonalnych. Na marginesie należy zaznaczyć, iż sam fakt, że mamy do czynienia $z$ adaptacją, wprowadza element intertekstualnego dialogu $\mathrm{z}$ tekstem źródłowym, co automatycznie zwiększa potencjał metafikcjonalny utworu, szczególnie w przypadku widza, który czytał wcześniej książki. Taki odbiorca ze względu na uprzednią wiedzę i wynikające $\mathrm{z}$ niej oczekiwania jest w większym stopniu ukierunkowany na porównywanie oryginału $\mathrm{z}$ adaptacją, a w konsekwencji na refleksję nad tym, jak utwór „został zrobiony” (Helman, 2014, s. 25-26) - gdy tymczasem widz pozbawiony takiej uprzedniej wiedzy jest bardziej skłonny do odbioru, który można by nazwać „naiwnym”, tj. klasycznego, konwencjonalnego „zanurzenia w opowieści”. Jest to oczywiście pewne uproszczenie; w rzeczywistości obydwa sposoby odbioru są możliwe w przypadku obu kategorii widzów (które zresztą można by dzielić dalej, np. na zagorzałych fanów książek i tych, którzy mają tylko niewyraźne wspomnienia z lektury) i zależą od wielu czynników, również indywidualnych. Nakreślenie takich ogólnych tendencji odbiorczych wydaje się jednak uprawnione.

Mimo to potencjał metafikcjonalny tkwiący niemal $z$ definicji w adaptacji nie jest dużo większy niż w jakimkolwiek innym tekście kultury, a jego uruchomienie wymaga autonomicznej decyzji odbiorcy, jeżeli sam tekst nie zawiera sygnałów, które zapraszałyby go do metafikcjonalnej gry. Takie sygnały są obecne w serialowej Serii niefortunnych zdarzeń. Należą do nich przede wszystkim liczne komentarze wskazujące na świadomość istnienia w obrębie filmowego medium, wypowiadane zarówno przez Snicketa (np. „Zalecam wyrzucenie urządzenia, na którym to oglądacie, do sadzawki" - Tracz, Sonnenfeld, 2019a), jak i przez postaci, które używają takich określeń jak „sezon” (Suarez-Pico, Welch, 2017), „wątki poboczne” (Tracz, Sonnenfeld, 2019b) albo „akcja” (Handler, Tracz, Welch, 2019)․ Warto zauważyć, że w książkowym

\footnotetext{
Dwa ostatnie przykłady pojawiają się tylko w oryginale („no more [...] side plots” i „sail back to where the action is"). W polskich napisach użyto bardziej neutralnych wyrażeń: „odchodzenie od sprawy” i „hen, ku przygodzie”. Redukcja aspektów metafikcjonalnych w tłumaczeniu serialu mogłaby stać się przedmiotem osobnej analizy.
} 
pierwowzorze wskazać można tylko jedną wypowiedź, w której postać zdradza znajomość konwencji narracyjnych i przy ich pomocy opisuje własną sytuację: Klaus, zamknięty w więzieniu wraz z siostrami, wyznaje, że pomóc im mógłby tylko deus ex machina (Snicket, 2001/2003b, s. 191). W serialu postaci działają w sposób naoczny, pozornie niezależny, nie podlegając werbalnej narracji, ale też wykazują się większą samoświadomością, przejmując część metafikcjonalnych funkcji, które w książkach są wyłączną domeną narratora.

Siłą rzeczy władza opowiadacza jest zatem w filmie mniejsza niż w powieściowym pierwowzorze, dlatego też wyrzeczenie się przez niego jakiejkolwiek mocy sprawczej i twórczej ma mniejszą wagę. Zarazem jednak serialowy Snicket przewyższa autorytetem swój książkowy pierwowzór. Wpływ na to ma spokojny, pewny siebie i budzący zaufanie wygląd Warburtona, którego trudno wyobrazić sobie, jak w napadzie rozpaczy bębni pięściami w dywan; wiarygodności dodaje mu sam fakt, że przez cały czas widzimy jego twarz, skrzętnie ukrywaną przez powieściowego Snicketa. Co więcej, pod koniec pierwszego sezonu, w odcinku Tartak tortur. Część 1 (Tracz, Welch, 2017), dokonuje drastycznej ingerencji w tok opowieści, gdy przerywa pełną napięcia scenę, przesuwając gwałtownie kamerę i wprowadzając niespodziewany zwrot akcji, który zmienia całkowicie sens jednego z wątków śledzonych przez widza od siedmiu odcinków (Kaczyńska, 2018, s. 82). Choć więc narrator w medium filmowym ma $z$ definicji mniejsze pole manewru niż w literaturze, serialowy Snicket w pierwszym sezonie sprawuje swoją okrojoną władzę znacznie pewniejszą ręką niż jego książkowy odpowiednik.

W kolejnych dwóch sezonach brak jest równie radykalnych zabiegów jak wspomniana manipulacja kamerą, a metafikcja wprowadzana jest wyłącznie przy pomocy komentarzy narratora lub postaci. Jednocześnie metaleptyczny status Lemony'ego Snicketa ulega dalszemu ograniczeniu: stopniowo traci on kompetencje narratorskie i zostaje mocniej osadzony w diegezie. Ma to związek z odmienną konstrukcją świata przedstawionego, który w adaptacji zostaje jednocześnie poszerzony i - paradoksalnie - skurczony. Z jednej strony, zgodnie z deklarowanym przez Tracza zamiarem „wyjaśniania tajemnic”, do fabuły serialu wprowadzono wątki nieobecne lub ledwie zasugerowane w powieściach, ukazujące działania członków WZS za kulisami historii Baudelaire’ów (Malina Weissman, Louis Hynes i Presley Smith), a także - za pośrednictwem retrospekcji - przedakcję, czyli wydarzenia z przeszłości. Dzięki temu widz dowiaduje się wprost, w jaki sposób doszło do schizmy i dlaczego miłosna historia Snicketa oraz Beatrycze (Morena Baccarin) zakończyła się nieszczęśliwie, a nawet dlaczego Hrabia Olaf (Neil Patrick Harris) zszedł na złą drogę. Dzięki przedstawieniu tych peryferii głównego wątku powstaje wrażenie rozbudowy 
świata przedstawionego - historia Baudelaire'ów stanowi tylko cząstkę owego świata. Inaczej niż w książkowym Końcu końców, opowieści nie mnożą się jednak bez końca i nie wymykają się poza zasięg narracji i możliwości percepcji, lecz splatają się ze sobą. Dobrym określeniem byłoby tu angielskie słowo streamlining: świat przedstawiony i fabuła zostają w porównaniu z powieścią uspójnione i ujęte $\mathrm{w}$ węższe, bardziej precyzyjne ramy, tworząc maszynerię działającą z większą sprawnością i konsekwencją.

\section{Eksplicytacja i ujednoznacznienie}

Przed wskazaniem wpływu, jaki taka konstrukcja diegezy ma na figurę Lemony'ego Snicketa, warto zauważyć, że udzielenie jednoznacznej odpowiedzi na większość zagadek wprowadzonych w fabule Serii niefortunnych zdarzeń w sposób oczywisty ogranicza swobodę interpretacyjną odbiorcy. Dotyczy to w pierwszej kolejności schizmy, której przyczyny, a nawet umiejscowienie $\mathrm{w}$ czasie są w powieściach określone w sposób bardzo niepewny. Z niektórych fragmentów wynikałoby, że doszło do niej za życia rodziców Baudelaire’ów, ale inne sugerują, że ludzkość rozdarta jest schizmą - lub schizmami - od zawsze. W Przedostatniej pułapce pojawia się pozornie precyzyjna wskazówka, kiedy dwie postaci w dwóch różnych scenach twierdzą, że schizma nastąpiła, gdy miały cztery lata (Snicket, 2005/2006a, s. 35, 187), co jednak tym bardziej przemawia za ahistorycznością i niedosłownością schizmy: większość ludzi nie ma wspomnień sprzed trzeciego roku życia, dlatego też osiągnięcie tego wieku stanowi dla nich początek świadomego istnienia. Umieszczając schizmę właśnie w tym momencie swojego życia, postaci przyznają, że trwa ona, odkąd pamiętają i odkąd zaczęly świadomie poznawać świat. To zaś przenosi poprzedzający schizmę czas zgody i szczęścia do sfery mitycznego „złotego wieku”. Czytelnik, jeśli zechce, może oczywiście odczytywać rozłam WZS dosłownie, jako punktowe wydarzenie w obrębie świata przedstawionego. Wiele szczegółów kieruje go jednak ku interpretacji szerszej i bardziej metaforycznej.

Podobnie jest z cukiernicą, poszukiwaną i pożądaną przez obydwie strony schizmy. Fakt, że trójka głównych bohaterów ani razu jej nie widzi i nie poznaje nigdy tajemnicy jej zawartości, umożliwia czytelnikowi stawianie różnych, równie uprawnionych hipotez. Może uznać, że w cukiernicy przechowywany jest zwykły cukier, tajne dokumenty albo antidotum przeciwko śmiercionośnemu grzybowi; może stwierdzić też, że istniało wiele cukiernic i każda postać szukała innej; może wreszcie dobrowolnie zrezygnować z prób odkrycia jedynej prawdy na rzecz docenienia czaru nierozwiązywalnej tajemnicy. Dopóki cukiernica 
nie zostanie otwarta, dopóty może zawierać wszystko i w ten sposób fascynować czytelnika, niczym Graal, który nie budziłby z pewnością tylu emocji zarówno badaczy literatury arturiańskiej, jak i laików, gdyby nie wieczne wątpliwości wokół jego pierwotnego znaczenia i możliwość wciąż nowych interpretacji.

W serialowej adaptacji cukiernica staje się mniej tajemnicza przez sam fakt pojawienia się na ekranie; przestaje być znakiem o mglistym desygnacie, a staje się biało-błękitnym naczyniem z motywem roślinnym. Można ją zobaczyć, a postacie mogą jej dotknąć i nawet do niej zajrzeć. Jej znaczenie, jak również przyczyny schizmy, a nawet powód, dla którego Hrabia Olaf stał się łotrem, zostają jednoznacznie wyjaśnione $\mathrm{w}$ dwóch ostatnich odcinkach serialu (Przedostatnia pułapka. Czesść 2 - Tracz, Sonnenfeld, 2019b; Koniec końców - Handler, Tracz, Welch, 2019) przy pomocy dialogów i retrospekcji: WZS pracowało nad śmiercionośnym grzybem, a substancję uodparniającą na jego zarodniki umieszczono w cukiernicy, która była własnością próżnej i chciwej Esmeraldy Szpetnej (Lucy Punch). Beatrycze i Lemony Snicket wykradają cukiernicę, zostają jednak przyłapani, a w zamieszaniu z ręki kobiety ginie ojciec Hrabiego Olafa. Snicket bierze winę na siebie i rozstaje się z Beatrycze, aby ją chronić.

Symboliczna interpretacja schizmy i cukiernicy nadal jest możliwa, w serialu są to jednak metafory, których warstwa dosłowna została zarysowana znacznie wyraźniejszą kreską niż w książce. Adaptacja konstruuje spójną i zwartą kompozycyjnie narrację, która ponadto zamyka całe dzieje WZS na przestrzeni kilkudziesięciu lat, co dodatkowo jeszcze ogranicza rozmiary świata przedstawionego. Podczas gdy czytelnik książek mógł jedynie domyślać się rozwiązania niektórych tajemnic, tropiąc rozproszone wzmianki i sugestie, a w niektórych przypadkach musiał pogodzić się z brakiem odpowiedzi, widz serialu otrzymuje je w sposób, który nie wymaga takiego wysiłku poznawczego.

Zakończenie adaptacji jest również łatwiejsze w odbiorze pod względem emocjonalnym. W powieści los wielu postaci pozostaje nieznany, a okoliczności, w których widziano je po raz ostatni, jak szalejący w hotelu pożar lub atak Wielkiej Niewiadomej, każą spodziewać się najgorszego. Dopowiedzenie ich historii zależy jednak od woli czytelnika, który - jeśli zechce - może w wyobraźni ułożyć szczęśliwe zakończenie. Może też podjąć metafikcjonalną refleksję, akceptując fikcyjność postaci i świata przedstawionego oraz dostrzegając własną rolę w twórczym akcie powoływania ich do istnienia poprzez wyobrażanie sobie ich losów i opowiadanie o nich. W serialu natomiast wiele wątków doczekuje się konwencjonalnego zakończenia: zaginieni krewni odnajdują się, a byli pomocnicy Hrabiego Olafa - znacznie sympatyczniejsi niż ich szef - osiągają sukces sceniczny. Lemony Snicket przedstawia wprawdzie te wydarzenia jako 
niepotwierdzone plotki, ale jego słowom towarzyszy legitymizujący je obraz. Narrator zostaje uwiarygodniony przez rzeczywistość widzialną i postrzeganą jako obiektywną (Ostaszewski, 2018, s. 214), a dzieje się to w tej samej chwili, gdy traci swoją narracyjną funkcję w historii Baudelaire'ów, schodząc do roli jednej z postaci.

\section{Od narratora do postaci, od postaci do narratora}

Jak już wspomniano, serialowy Lemony Snicket sprawia wrażenie bardziej godnego zaufania niż jego książkowy pierwowzór, a retrospekcje, w których pojawia się jego młodsza wersja, osadzają go mocniej w świecie przedstawionym. Warto zacytować tu jego wyznanie miłości podczas pożegnania z Beatrycze:

Będę cię kochał, jeśli nigdy już cię nie zobaczę, i będę cię kochał, jeśli będę widywał cię co wtorek. Będę cię kochał tak, jak góra lodowa kocha statek, a pasażerowie kochają szalupę, jak pole bitwy kocha młodych mężczyzn, i jak miętówki kochają twoją alergię. Będę cię kochał, gdy się postarzejemy, co właśnie się stało, i stało się jeszcze raz, i będzie dziać się dalej. Będę cię kochał, póki wszystkie pożary nie zostaną ugaszone, wszystkie domy odbudowane, a wszystkie szyfry i serca złamane (Tracz, Sonnenfeld, 2019b ${ }^{8}$ ).

Na takie niebanalne porównania Beatrycze może odpowiedzieć tylko oczarowanym: „Zawsze umiałeś dobierać słowa” (Tracz, Sonnenfeld, 2019b) i poddać się namiętnemu pocałunkowi. Różnica między elokwentnym melancholikiem granym przez Patricka Warburtona a książkowym Snicketem staje się tym wyraźniejsza, gdy weźmie się pod uwagę, że jego wyznanie stanowi bardzo krótki fragment The Beatrice Letters (Snicket, 2006b, b.p.), niewydanej po polsku książki spoza głównej serii, stanowiącej zbiór listów od Lemony’ego Snicketa do Beatrycze, matki Baudelaire'ów, oraz do Lemony'ego Snicketa od „Beatrycze Młodszej”, ich podopiecznej, która urodziła się w Końcu końców. Wyznanie miłości w The Beatrice Letters to ciągnący się przez ponad trzy strony słowotok, pełen piętrowych i łańcuszkowych porównań, których histeryczna obfitość i absurdalność wywołują efekt komiczny. Monolog ograniczony w adaptacji do kilku zdań, wypowiedzianych niskim, wzruszonym głosem, powoduje natomiast, że mężczyzna nie jest już werbalną konstrukcją parodiującą topos

8 Nie skorzystano tu $\mathrm{z}$ oficjalnego polskiego tłumaczenia ze względu na pojawiające się w nim nieścisłości. 
zakochanego artysty, lecz postacią, którą należy postrzegać zupełnie serio, $\mathrm{w}$ konwencji realizmu iluzyjnego.

O ile książkowy Snicket zstępuje na intradiegetyczny poziom historii Baudelaire’ów (chronologicznie wcześniejszy wobec jego funkcji narratora) w jednej krótkiej i niejednoznacznej scenie, która jedynie sugeruje jego tożsamość, o tyle jego serialowy odpowiednik pojawia się w tym głównym nurcie opowieści kilkakrotnie, w interakcji z różnymi postaciami. Baudelaire'om podaje swoje pełne imię i nazwisko, wyjaśniając im szczegółowo, dlaczego przyjechał po nich taksówką. Również brak bardziej zdecydowanej interwencji z jego strony otrzymuje racjonalne intradiegetyczne wyjaśnienie, a mianowicie lęk przed aresztowaniem. Snicket jako postać należąca do świata przedstawionego nie jest mglistym cieniem na marginesie, jak to było w książkach, lecz w pełni naświetlonym bohaterem o określonych dążeniach i obawach, mocno osadzonym w diegezie.

W tym samym odcinku (Przedostatnia pułapka. Część 2 - Tracz, Sonnenfeld, 2019b) Snicket traci swoją funkcję narratora opisującego ex post dzieje Baudelaire'ów, przyznaje bowiem, że nie wie, co stało się z nimi po ucieczce z płonącego Hotelu Ostateczność. Jego horyzont poinformowania (Ostaszewski, 2018, s. 19) zostaje zredukowany, a wydarzenia na wyspie w Końcu końców (Handler, Tracz, Welch, 2019) biegną całkowicie niezależnie od niego. On sam, przygnębiony niepowodzeniem swojej misji i poczuciem utraconego celu, nie przestaje zwracać się do widza w monologach, które zawsze w jakiś sposób odnoszą się do tego, co właśnie przeżywają Baudelaire’owie. Tym samym ostatni odcinek serialu przesuwa się jeszcze bardziej w stronę realizmu iluzyjnego. Ponieważ nic w obrębie utworu nie zwraca uwagi widza na zbieżność fabuły z komentarzem Snicketa (pozbawioną wszak intradiegetycznego wytłumaczenia), konwencje narracyjne stają się niewidoczne, a metafikcjonalny aspekt odcinka ograniczony. Fakt, że odbiorca, do którego Snicket bezpośrednio się zwraca i z którym do tej pory dzielił świadomość swojej przynależności do serialowego medium, nagle przewyższa go wiedzą, ponieważ ogląda sceny niedostępne dla zdegradowanego narratora, również nie doczekuje się eksplicytacji, która miałaby wydźwięk metafikcjonalny.

Status Snicketa jako jednej z postaci związanych nierozerwalnie ze światem przedstawionym zostaje jeszcze wzmocniony za sprawą wprowadzonego w serialowym Końcu końców (Handler, Tracz, Welch, 2019) wątku dziesięcioletniej Beatrycze Beaudelaire (Angelina Capozzoli). Zaczerpnięto go ze wspomnianych już The Beatrice Letters (Snicket, 2006b), w których osamotniona Beatrycze po utracie kontaktu z Baudelaire’ami próbuje odnaleźć Snicketa, on jednak nieustannie jej się wymyka. Zamykający książkę list pozostawia czytelnika w zawieszeniu: jest to ze strony Beatrycze ostatnia prośba o rozmowę, 
a jej spełnienie pozostawia się decyzji czytelnika. W serialu również ta niepewność doczekała się rozwiązania, ponieważ Snicket nader ochoczo zgadza się na spotkanie, podczas którego Beatrycze zaczyna opowiadać mu historię Baudelaire'ów, zwłaszcza zaś - ich przygody po opuszczeniu wyspy.

Jest to zakończenie znacznie bardziej optymistyczne niż w książkach, a przy tym dowartościowujące dziecko, które przejmuje rolę narratora, dzięki czemu historia może toczyć się dalej. Odwrócona zostaje tradycyjna relacja władzy między dorosłym, który opowiada, a dzieckiem, które musi biernie słuchać. Na jej miejsce pojawia się dialog, w którym przewagę ma dziesięcioletnia dziewczynka9 Choć sytuacja ta nie jest pozbawiona metafikcjonalnych aspektów, nie doprowadzają one do rozsadzenia fikcji, jak dzieje się to w książkowym tekście źródłowym. Opowieść wydaje się toczyć niezależnie od narracji Beatrycze, która jedynie relacjonuje wydarzenia, postrzegane jako obiektywnie mające miejsce w świecie przedstawionym. Nawet uwolniwszy się od narratora, historia nie uwalnia się od konwencji narracyjnych, które doprowadzają ją bezpiecznie do szczęśliwego zakończenia. Snicket stwierdza, że niektóre opowieści trwają dalej, nawet gdy zamilknie osoba, która je opowiada (Handler, Tracz, Welch, 2019) - i w wizualnym medium tak dzieje się rzeczywiście, ponieważ werbalna aktywność narratora nie jest w nim konieczna. Dzieje się tak z powodu skurczenia i większej dosłowności świata przedstawionego, harmonijnego zakończenia wątków pobocznych, a przede wszystkim - roli narratora innej niż w powieści.

Narrator osobowy nie stanowi elementu niezbędnego ani w filmie, ani w literaturze, ale podczas gdy narrator literacki posługuje się słowem, ten kinematograficzny ma do dyspozycji środki wizualne, takie jak montaż czy inscenizacja (Ostaszewski, 2018, s. 36). W Serii niefortunnych zdarzeń mamy jednak do czynienia z upostaciowionym narratorem, który w zależności od medium zajmuje różną pozycję. W powieściach nie istnieje żadna inna instancja kreująca świat przedstawiony oprócz opowiadania narratora (choćby on sam temu zaprzeczał) ${ }^{10}$. Serialowy Snicket również posługuje się słowem, może jednak

9 Na marginesie warto zauważyć, że w adaptacji również Baudelaire’owie jako narratorzy własnej opowieści spotykają się z uznaniem wcześniej niż w literackim tekście źródłowym: podczas gdy w powieści mają szansę opowiedzieć własną historię dopiero wtedy, gdy piszą kronikę wyspy, w serialu mogą to zrobić już podczas procesu w Hotelu Ostateczność, a ich wystąpienie zostaje nagrodzone oklaskami zgromadzonych, chociaż uznanie to okazuje się czysto deklaratywne i nie idą za nim żadne konkretne działania na rzecz dzieci.

10 Alternatywne tryby narracji (w tym przede wszystkim narracja epistolarna) pojawiają się w książkach pobocznych: Lemonym Snickecie. Nieautoryzowanej autobiografii (Snicket, 2002/2004a) i The Beatrice Letters (Snicket, 2006b), jednak główna seria pozostaje pod tym względem jednolita. 
również zatrzymać albo zakłócić akcję dzięki stop-klatce albo wspomnianej już jednorazowej uzurpacji kamery. Według cytowanej przez Ostaszewskiego (2018, s. 32-33) typologii New Vocabularies in Film Semiotics (Stan, Burgoyne, Flitterman-Lewis, 1992, s. 97) wykazuje on pewne cechy narratora ekstradiegetycznego, manipulującego środkami filmowymi, i heterodiegetycznego, niebiorącego udziału w opowiadanej przez siebie historii (do czasu); im bliżej jednak końca serialu, w tym większym stopniu staje się narratorem homodiegetycznym, należącym do opowieści i do świata przedstawionego, o coraz bardziej ograniczonym horyzoncie poinformowania, aż ostatecznie zostaje zastąpiony w tej roli przez inną postać. Nawet gdy narracja wymyka się spod jego kontroli, pieczę nad nią ma nadal bezosobowy narrator kinematograficzny. W konsekwencji nie ulega ona rozpadowi, jak dzieje się to w książce.

\section{Zakończenie}

Nie wydaje się, by decyzje podjęte przez twórców adaptacji i skutkujące jej bardziej optymistyczną i jednoznaczną wymową wynikały z chęci dostosowania się do odbiorcy dziecięcego; na platformie Netflix serial oznaczony jest jako „dla dzieci” (od siódmego roku życia), jednak Daniel Handler zawsze sprzeciwiał się lekceważeniu zdolności percepcyjnych młodych odbiorców (np. Hogan, 2000), a Joe Tracz (2019) jako główną przyczynę modyfikacji podaje różnicę medium. Pozostaje kwestią dyskusyjną, czy - jak twierdzi ten ostatni - niemożliwa byłaby adaptacja Serii niefortunnych zdarzeń, w której przy pomocy środków właściwych językowi filmu osiągnięto by taki sam poziom niejednoznaczności i refleksji metafikcjonalnej jak w powieści. Jasne jest natomiast, że choć serial dystrybuowany przez Netflix gra z klasycznymi konwencjami narracyjnymi, nigdy nie kwestionuje ich całkowicie. Nie doprowadza do ich zerwania i rozpadu, i koniec końców dostosowuje się do nich, dając satysfakcjonujące zakończenie odbiorcy, który nie chce wychodzić poza granice niepisanego fikcjonalnego paktu Gérarda Genette’a i pragnie dowiedzieć się po prostu, „co się tak naprawdę wydarzyło”. 


\section{Bibliografia}

Austin, S. (2013). Performative metafiction: Lemony Snicket, Daniel Handler and The End of A Series of Unfortunate Events. The Looking Glass, 17(1). Pobrane z: https:// www.lib.latrobe.edu.au/ojs/index.php/tlg/article/view/387/381.

b.a. (b.d.). The End. Goodreads. Pobrane z: https://www.goodreads.com/book/ show/65112.The_End.

Carroll, L. (1999), Alicja po tamtej stronie lustra (J. Kozak, tłum.). Warszawa: Prószyński i S-ka. (wyd. oryg. 1871).

Currie, M. (1995). Introduction. W: M. Currie (red.), Metafiction (s. 1-18). New York, NY: Longman.

De Bruyn, D. (2006). Różnica między polskim pojęciem „autotematyzm” a amerykańskim pojęciem „metafiction”. Studia Universitatis Mariae Curie-Skłodowska, Sectio FF - Philologiae, 24, 47-54.

Genette, G. (2004). Métalepse. De la figure à la fiction. Paris: Seuil.

Handler, D., Lam, R., Sonnenfeld, B. (prod.). (2017-2019). A series of unfortunate events [Seria niefortunnych zdarzeń] [serial telewizyjny]. Los Gatos, CA: Netflix.

Handler, D. (scen.), Teplitzky, J. (reż.). (2019). Slippery slope: Part one [Zjezdne zbocze. Część 1] [odcinek serialu telewizyjnego]. W: D. Handler, R. Lam, B. Sonnenfeld (prod.), A series of unfortunate events [Seria niefortunnych zdarzeń]. Los Gatos, CA: Netflix.

Handler, D., Tracz, J. (scen.), Welch, B. (reż.). (2019). The end [Koniec końców] [odcinek serialu telewizyjnego]. W: D. Handler, R. Lam, B. Sonnenfeld (prod.), A series of unfortunate events [Seria niefortunnych zdarzeń]. Los Gatos, CA: Netflix.

Helman, A. (2014). Twórcza zdrada. Filmowe adaptacje literatury (wyd. 2 zm. i poszerz.). Poznań: Ars Nova.

Hogan, R. (2000). Daniel Handler. Beatrice Interview. Pobrane z: http://www.beatrice. com/interviews/handler.

Hutcheon, L. (1984). Narcissistic narrative: The metafictional paradox. New York, NY, London: Methuen University Paperback.

Kaczyńska, B. (2018). Metafiction in children's literature and its adaptation on screen: The case of Lemony Snicket's A Series of Unfortunate Events. New Horizons in English Studies, 3, 71-85. https://doi.org/10.17951/nh.2018.71.

Loewe, I. (2016). Tekst okładki w książce dla młodego odbiorcy. Analiza genologiczno-stylistyczna. Stylistyka, 25, 371-388.

MacDonald, L., Parkes, W. F., Van Wyck, J. (prod.), Silberling, B. (reż.). (2004). A series of unfortunate events [Lemony Snicket: Seria niefortunnych zdarzeń] [film]. Los Angeles, CA: Paramount Pictures.

Magnusson, K. (2012). Lemony Snicket's A Series of Unfortunate Events: Daniel Handler and marketing the author. Children's Literature Association Quarterly, 37(1), 86-107. https://doi.org/10.1353/chq.2012.0013. 
Melville, H. (2002). Moby Dick. London: Wordsworth Classics. (wyd. oryg. 1851).

Ostaszewski, J. (2018). Historia narracji filmowej. Kraków: TAiWPN Universitas.

Slany, K. (2016). Groza w literaturze dziecięcej. Od Grimmów do Gaimana. Kraków: WN UP.

Snicket, L. (2002a). Przykry początek (J. Kozak, tłum.). Warszawa: Egmont. (wyd. oryg. 1999).

Snicket, L. (2002b). Gabinet gadów (J. Kozak, tłum.). Warszawa: Egmont. (wyd. oryg. 1999).

Snicket, L. (2002c). Ogromne okno (J. Kozak, tłum.). Warszawa: Egmont. (wyd. oryg. 1999).

Snicket, L. (2002d). Tartak tortur (J. Kozak, tłum.). Warszawa: Egmont. (wyd. oryg. 2000).

Snicket, L. (2003a). Winda widmo (J. Kozak, tłum.). Warszawa: Egmont. (wyd. oryg. 2001).

Snicket, L. (2003b). Wredna wioska (J. Kozak, tłum.). Warszawa: Egmont. (wyd. oryg. 2001).

Snicket, L. (2003c). Szkodliwy szpital (J. Kozak, tłum.). Warszawa: Egmont. (wyd. oryg. 2001).

[Snicket, L.]. (2004a). Lemony Snicket. Nieautoryzowana autobiografia (J. Kozak, tłum.). Warszawa: Egmont. (wyd. oryg. 2002).

Snicket, L. (2004b). Zjezdne zbocze (J. Kozak, tłum.). Warszawa: Egmont. (wyd. oryg. 2003).

Snicket, L. (2006a). Przedostatnia pułapka (J. Kozak, tłum.). Warszawa: Egmont. (wyd. oryg. 2005).

Snicket, L. (2006b). The Beatrice Letters. New York, NY: HarperCollins.

Snicket, L. (2007). Koniec końców (J. Kozak, tłum.). Warszawa: Egmont. (wyd. oryg. 2006).

Statkiewicz-Zawadzka, K. (2010). „Let's Make a Meta-movie”. Metalepsy i inne gry narracyjne Spike'a Jonze'a i Charliego Kaufmana. Kwartalnik Filmowy, 71-72, 230-246.

Suarez-Pico, T. (scen.), Welch, B. (reż.). (2017). The miserable mill: Part two [Tartak tortur. Część 2] [odcinek serialu telewizyjnego]. W: D. Handler, R. Lam, B. Sonnenfeld (prod.), A series of unfortunate events [Seria niefortunnych zdarzeń]. Los Gatos, CA: Netflix.

Tołstoj, L. (1984). Anna Karenina (K. Iłłakowiczówna, tłum.). Warszawa: PIW. (wyd. oryg. 1877).

Tracz, J. (2019). The annotated interview: 667 Dark Avenue interviews Joe Tracz (with answers). 667 Dark Avenue. Pobrane z: http://asoue.proboards.com/thread/35807/ dark-avenue-interviews-tracz-answers.

Tracz, J. (scen.), Peristere, L. (reż.). (2018). Carnivorous carnival: Part one [Krwiożerczy karnawał. Część 1] [odcinek serialu telewizyjnego]. W: D. Handler, R. Lam, 
B. Sonnenfeld (prod.), A series of unfortunate events [Seria niefortunnych zdarzeń]. Los Gatos, CA: Neflix.

Tracz, J. (scen.), Sonnenfeld, B. (reż.). (2019a). Penultimate peril: Part one [Przedostatnia pułapka. Część 1] [odcinek serialu telewizyjnego]. W: D. Handler, R. Lam, B. Sonnenfeld (prod.), A series of unfortunate events [Seria niefortunnych zdarzeń]. Los Gatos, CA: Netflix.

Tracz, J. (scen.), Sonnenfeld, B. (reż.). (2019b). Penultimate peril: Part two [Przedostatnia pułapka. Część 2] [odcinek serialu telewizyjnego]. W: D. Handler, R. Lam, B. Sonnenfeld (prod.), A series of unfortunate events [Seria niefortunnych zdarzeń]. Los Gatos, CA: Neflix.

Tracz, J. (scen.), Welch, B. (reż.). (2017). The miserable mill: Part one [Tartak tortur. Część 1] [odcinek serialu telewizyjnego]. W: D. Handler, R. Lam, B. Sonnenfeld (prod.), A series of unfortunate events [Seria niefortunnych zdarzeń]. Los Gatos, CA: Netflix.

Waugh, P. (1984). Metafiction: The theory and practice of self-conscious fiction. New York, NY: Methuen.

Wright, R. (1980). Syn swego kraju (Z. Kierszys, tłum.). Warszawa: PIW. (wyd. oryg. 1940). 